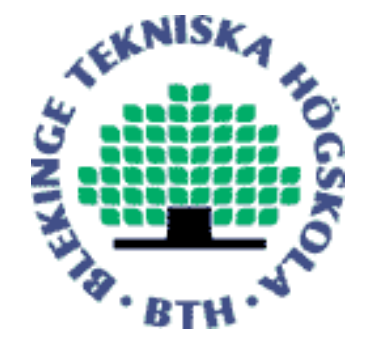

Copyright (C) 2014 IEEE.

Citation for the published paper:

Building up a Virtual Community for Home-Based Chronic Diseases Healthcare

Yan $\mathrm{Hu}$, Guohua Bai

UsARE2014

2014 Karlskrona

This material is posted here with permission of the IEEE. Such permission of the IEEE does not in any way imply IEEE endorsement of any of BTH's products or services Internal or personal use of this material is permitted. However, permission to reprint/republish this material for advertising or promotional purposes or for creating new collective works for resale or redistribution must be obtained from the IEEE by sending a blank email message to pubs-permissions@ieee.org.

By choosing to view this document, you agree to all provisions of the copyright laws protecting it. 


\section{Building up a Virtual Community for Home-Based Chronic Diseases Healthcare}

\author{
Yan $\mathrm{Hu}$ \\ Department of Creative Technologies \\ Blekinge Institute of Technology \\ 37179,Karlskrona, Sweden \\ yhx@bth.se
}

\author{
Guohua Bai \\ Department of Creative Technologies \\ Blekinge Institute of Technology \\ 37179, Karlskrona, Sweden \\ gba@bth.se
}

\begin{abstract}
With the development of Internet, social networks get more and more popular, it brings us an idea of designing a virtual community for home-based chronic diseases healthcare. In this paper, we conduct a questionnaire to gather the requirements of the community and describe them with user stories. Afterwards, a conceptual prototype is developed based on the requirements. The proposed virtual community involves healthcare providers, healthcare recipients and other people relevant to the home-based healthcare into one platform. It will solve the interoperability problems of current healthcare systems, as well as provide a technical solution of home-based healthcare.
\end{abstract}

Index Terms-Virtual community, home-based healthcare, chronic disease, requirements.

\section{INTRODUCTION}

The success of social network like Facebook and Twitter let people with same interests build up a virtual community to communicate with each other no matter the differences of geographical distribution. A virtual community is a social network that people interact through specific social media. It is crossing geographical and political boundaries in order to pursue the same interests or goals [1].

Nowadays, chronic diseases affect the population all over the world. According to the World Health Organization (WHO) [2], chronic diseases represent $60 \%$ of all deaths in the world, which are the leading cause of mortality. However, chronic diseases can only be controlled but not cured [3]. Since they last long time duration, provide efficient chronic diseases healthcare become a worldwide goal in healthcare domain. In fact, the patients suffered from chronic diseases have to be monitored from time to time. That's very high cost, time consuming and inconvenient for most of patients, especially the limitations to patients' daily activities and inconvenience of aged people. Meanwhile most of the cases for chronic diseases do not need urgent medical diagnosis and treatments [4]. If moving the chronic diseases healthcare from hospital-based to home-based, it may save a lot of time and resources, and providing efficient healthcare.

Thanks to the development of information and communication technology (ICT), the feasibility of home based eHealth has been highly raised [4]. Many physiological signals can be measured by individuals in their living environments during daily activities [5]. If there is a virtual online community for people with chronic diseases, the home based healthcare could enable people independent living at home and improves the quality of lives for them. By this community, healthcare recipients can not only communicate with each other, but also with healthcare providers, families and other research institutions quickly and directly.

This paper starts with a questionnaire of people over 55 with one or more chronic diseases to gather the patientscentered requirements of online community. According to the results of questionnaire, we describe the functional requirements in user stories style. The non-functional requirements are discussed in section 4. Finally, a prototype of virtual community for come-based chronic diseases healthcare is developed. The last section is our discussion of this virtual community and the limitations of our works.

\section{REQUIREMENTS COLLECTION OF COMMUNITY}

A good online virtual community could not only perform as the functions of community, but also can integrate some healthcare tools. In this community, patients-centered selfmanagement is the main trend for home-based chronic diseases healthcare. There are already some commercial or researchbased solutions for the mentioned way of self-management. For instance, HealthVault [6], launched by Microsoft, is a webbased PHR system to store and maintain health and fitness information. There are a lot of specific third-party applications, such as blood pressure management tool or medical image viewer, as well as hundreds of devices, such as blood glucose meter, blood pressure monitor, could cooperate with this community to record health data and manage health.

In order to meet most users' needs when designing the online virtual community, we begin with requirements specification. There are two types of requirements in website design and software engineering, functional requirements and non-functional requirements [7]. As we mentioned above, in home-based healthcare, patients are the center of the healthcare, as well as the main users. So we selected online questionnaires from the potential healthcare recipients as the key datagathering technique.

Questionnaires include a series of questions designed to elicit specific information from the users. Well-designed questionnaires are better way to get answers to specific questions from a group of people, especially for people who are infeasible to visit them all [7]. In this case, the questions are mostly designed for functional requirements in the healthcare recipients' perspective. In our questionnaires, we publish our questions on surveymenkey.com as the electronic form. The respondents are limited of age above 55 with one or more chronic diseases. We send out the questionnaires through some social network websites, such as patientslikeme and facebook. 
It contains 10 questions mixed with simple Yes or No questions, choose from a set of pre-supplied answers and open comment questions. In the end, 25 valid responds are gathered, most of the respondents are from US and Sweden.

\section{A. Problems in Current Healthcare}

The first open question is about the problems they faced in their current healthcare, almost all the respondents mentioned that the long time waiting for doctors' appointments make them uncomfortable. "The resource is limited. It means I need to spend more time to wait the healthcare service. And when I waiting for the doctor, I really also need suggestions to keep my body stable, not be more serious." "Really long queue in every time when I visit some hospitals". In some countries like Sweden, the shortage of healthcare providers leads to the long waiting query of hospitals, sometimes the patients lose the best time for diagnoses and treatments. Another big problem proposed by the respondents is lack of information sharing among healthcare providers, when they come to the new healthcare organizations, their historical healthcare records were difficult to find. "When I went to another hospital which I never visited, the doctor didn't know my health history, if I have hypersensitivity reaction for some drugs, he didn't know, so this may produce some healthcare problems. If I need to have a new scratch test, it wastes time and resource." "There is no shared information among the hospitals. It cannot help the care providers to communicate to each other." This brings the healthcare recipients overlap check-ups, which is a time and resources waste. Besides above two, some respondents also point out the location of healthcare center is far away from their home, it is inconvenient for them to go to healthcare centers frequently.

\section{B. Views of Online Healthcare Community}

When asking about the time spend on Internet per day, $60 \%$ spend more than 6 hours, which means Internet has already been an essential part of their daily lives. Because of the high rate of using Internet, the online healthcare community is acceptable. All the respondents would like to have an online healthcare community which they could chat with all stakeholders related to their healthcare through one platform. The results on which people they want to chat with through the online community are doctors $(96 \%)$, other healthcare providers $(84 \%)$, other people with same symptoms $(72 \%)$, family members $(68 \%)$ and some healthcare research institutions (64\%).

\section{Online Community Functions Design}

In Question 5 to 8, we ask about some functions of the online healthcare community, the result is shown in Fig.1. From the figure, we find out that all functions we plan to develop are supported by most of the respondents. Question 10 is an open question on other functions they are willing to have, online simple diagnose was one of the most desirable functions. Free seminars and lectures for healthcare is another suggestion by most of the respondents. "Simple medical suggestions and little medical diagnosis", "Diagnosis, chatting, forum, online seminar" "diagnosis online" and "Healthcare lecture" were mentioned most. In addition, fast contact and response, risk prediction, decision support systems and nearby healthcare centers information were also suggested. In Question 9, the respondents were asked which non-functional features are important for them as the users of online community, availability (100\%), usability (88\%), security (88\%) and privacy $(84 \%)$ are all got very high supports.

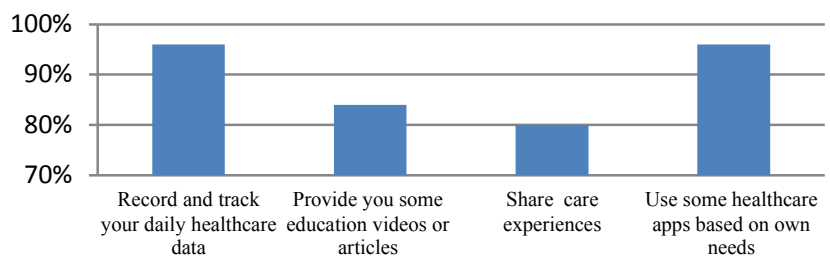

Fig. 1. Functions of the online healthcare community

\section{MAIN FUNCTIONAL REQUIREMENTS}

Since one of the aims of building up this online care community is to encourage the care recipients be the main forces of their home-based healthcare. The requirements of healthcare providers are gathered mainly based on our previous interviews and informal discussions with doctors, nurses and homecare providers.

In this section, we list the simple functional requirements of the online virtual community through our questionnaires. Table 1 is the requirements list of the online community design. We use the user stories style to describe them for easy understanding and quick changes. A user story is used with agile software development methodologies. It contains one or more sentences in the everyday language to describe what an end user to do or need as part of function [8].

\section{NON-FUNCTIONAL RESEQUIREMENT ISSUES}

Non-functional requirement is a requirement used to measure the operation of a system, rather than specific behaviors [9]. In software systems, non-functional requirement is also considered as quality attributes. For our community design, usability, security and privacy, as well as availability are main issues of non-functional requirements [10].

Usability: The main users of this online community are elderly people with one or more chronic diseases, it should be extremely simple to use and easy to learn. As a result, the user interface design of our online community will follow "Ten usability heuristics [11]" as a guideline.

Privacy: The patient health information includes personal information, details of medical history, symptoms, treatments, associated diseases or even the family health history. It is important to ensure that only the patients can authorize exactly who can view the shared health information and for what purposes [12]. All the information generated by a patient is not at the same sensitive level. Data segmentation may provide a method to protect specific sections of health information while giving choices to patients, and abiding requirements of legal. Technical consideration and definition of sensitive information have to be addressed when segmenting data [13].

Security: Security is assurance that only authorized persons or entities can access to patients' data. Employees' illegitimate access and theft is one of the most frequent reasons of data leakage [12], as well as innocent disclosure because of system problems. Another issue is unauthorized access and malicious 
attacks from outside. So the encryption, identification and access control of patient health data are not optional of the online community development [12].

Availability: As an online healthcare community, it should be available in 24 hours every day. The authorized users could be able to access the community anytime anywhere.

\section{TABLE 1 REQUIREMENTS LIST}

\begin{tabular}{|c|c|}
\hline $\begin{array}{l}\text { Users } \\
\text { types }\end{array}$ & Descriptions \\
\hline \multirow{6}{*}{$\begin{array}{l}\text { All users } \\
\text { (As a } \\
\text { user) }\end{array}$} & $\begin{array}{l}\text { I want to register an account on the online healthcare } \\
\text { community and choose my use type based on different roles. }\end{array}$ \\
\hline & $\begin{array}{l}\text { When I login my account, the information page will be } \\
\text { displayed automatically according to my user type. }\end{array}$ \\
\hline & $\begin{array}{l}\text { I want to have online chat with my contact persons like care } \\
\text { providers, care recipients, family members and so on. }\end{array}$ \\
\hline & I want to have alarms to reminder my care activities. \\
\hline & $\begin{array}{l}\text { I want to have the contract persons address book with the } \\
\text { detail contact information. }\end{array}$ \\
\hline & $\begin{array}{l}\text { I want to share some useful healthcare information to my } \\
\text { contact persons. }\end{array}$ \\
\hline \multirow{8}{*}{$\begin{array}{l}\text { Care } \\
\text { recipients } \\
\text { (As a } \\
\text { care } \\
\text { recipient) }\end{array}$} & $\begin{array}{l}\text { I want to contact my care providers directly through the } \\
\text { online community for simple diagnose and care suggestions. }\end{array}$ \\
\hline & I want to have some videos of healthcare education lectures. \\
\hline & $\begin{array}{l}\text { I want to record my daily health data myself in the } \\
\text { community and share it to people who I want to share with. }\end{array}$ \\
\hline & $\begin{array}{l}\text { I want to have some tools to trace and check my care data, } \\
\text { as well as to print it out when necessary. }\end{array}$ \\
\hline & $\begin{array}{l}\text { I want to share my care experiences with people who have } \\
\text { the same symptoms as me. }\end{array}$ \\
\hline & I want to book a doctor appointment online. \\
\hline & $\begin{array}{l}\text { I want to integrate some healthcare relevant apps in the } \\
\text { community based on my individual needs. }\end{array}$ \\
\hline & $\begin{array}{l}\text { I want to have the address and opening time information of } \\
\text { the nearest healthcare centers }\end{array}$ \\
\hline \multirow{5}{*}{$\begin{array}{l}\text { Care } \\
\text { providers } \\
\text { (As a } \\
\text { care } \\
\text { provider) }\end{array}$} & I want to share some care information with other providers. \\
\hline & $\begin{array}{l}\text { I want to have some online seminar with other providers and } \\
\text { my care recipients. }\end{array}$ \\
\hline & $\begin{array}{l}\text { I want to update the care histories of my recipients to the } \\
\text { online community. }\end{array}$ \\
\hline & $\begin{array}{l}\text { I want to have some support decision systems to help me for } \\
\text { diagnoses and treatments. }\end{array}$ \\
\hline & I want to have a list of every \\
\hline
\end{tabular}

\section{PROTOTYPE DESIGN}

With the requirements specified above, we develop a simple prototype for conceptual design. It is a kind of horizontal prototyping, which refers that the prototype should cover the user interactions' functions as many as possible with not so deep details [14]. In our prototype, the roles of users are divided into three types: healthcare recipient, healthcare provider and others like family members and researchers. The user type is selected by the users in registration. After successfully registered, the information related to the role of the community will be displayed based on the user types. The role of the users decides the information and activities they can have in the online community.

When the user finished registration and login in to his or her account by user name and password, the system will automatically turns the user to his or her sites according to the role. As shown in Fig. 2, Anna Nilsson is a healthcare recipient, and the profile site has her basic information and the information relevant to her, like her healthcare community, tools and rules. The contacts list in the middle has detail information of all her care providers and other people relevant to her healthcare. In the right-bottom part, she can note her main symptoms so that people has same conditions can easily find her and share with each other's care experiences.

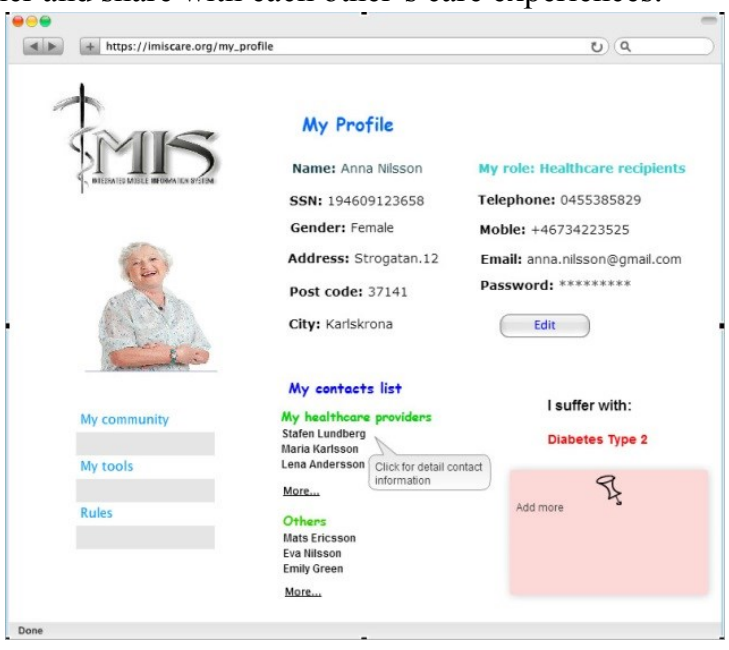

Fig. 2. Healthcare recipients profile

The page "my community" is designed based on the needs of questionnaires respondents, see Fig. 3, all the contact persons are listed in the right contain healthcare providers, family members and others. They can chat with each other when they are online, so the healthcare recipients can get the feedbacks immediately form the healthcare providers without visiting any healthcare organizations. The community also provides a space for users to post some discussions, videos, websites etc. to share with their contacts. Another important function is that the community will always show the nearest healthcare centers information based on the gathered user geographical data. The scheduled care activities will be shown rolling in red to reminder the recipients.

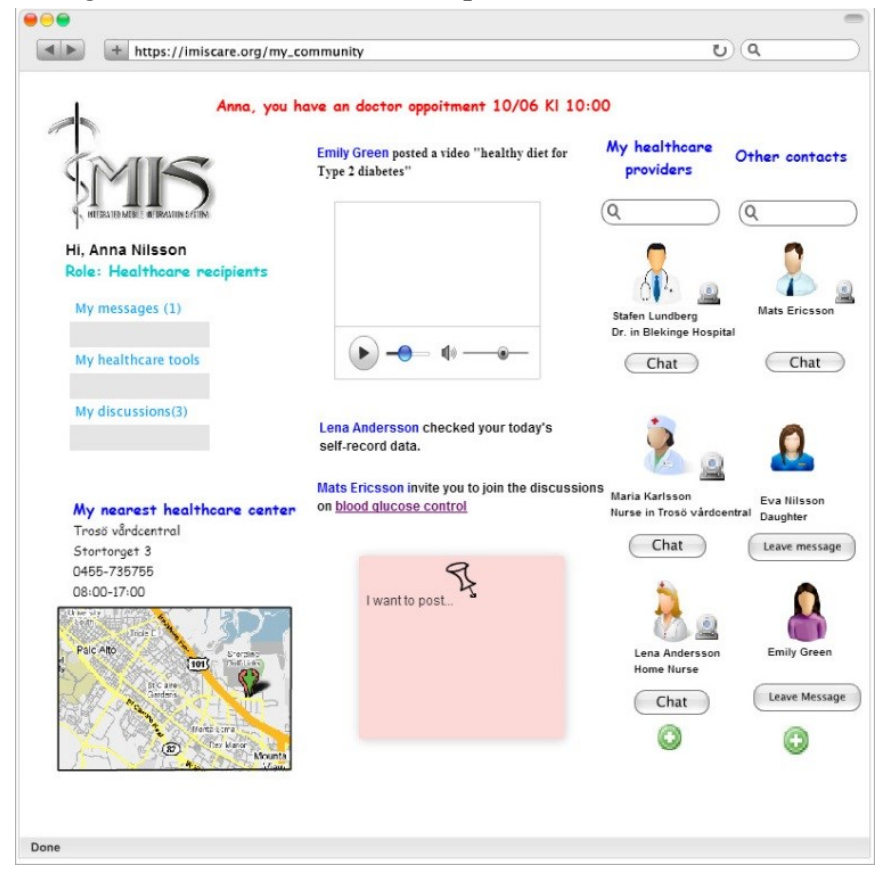

Fig. 3. Healthcare community page 
The most important function of home-based healthcare community is to provide a self-management platform for the healthcare revivers. In our design, it is in the recipients' "My tools" page, shown in Fig. 4, the recipients update their basic physiological parameters, emotions and diet daily for record and trace. The authenticated healthcare providers can access the data and give some suggestions to recipients. The recipient can print out this data in a long period as well to show the doctors and other care providers when they have an appointment. Online appointment is also proposed to reduce the waiting time of meeting doctors. In addition, personalized tools are introduced to the users so that they can use them based on their own needs. The healthcare providers' tools page including functions of updating care history, appointment remaindering, decision support systems for diagnoses and treatments and so on.



Fig. 4. Healthcare recipients tool page

\section{DISCUSSION AND LIMITATION}

The above prototype presents a general view of the community, which is a patients-centered virtual community for home-based chronic diseases care. The design integrates healthcare recipients, healthcare providers and other related people into one community. The virtual community makes it possible to have only one platform for all the stakeholders who contribute to home-based chronic diseases. It will solve the interoperability problems of current healthcare systems, as well as provide a technical solution of home-based healthcare. There are a lot of ICT technologies in eHealth applications, in our case, we believe cloud computing would be an applicable technology. Cloud computing is beginning to demonstrate its great potentials in our daily healthcare due to its powerful services in managing big data, accessibility, flexibility, scalability and cost-effectiveness services. Cloud technology mitigates the need to invest in IT infrastructure, by providing access to hardware, computing resources, applications, and services on a 'per use' model. And thus it dramatically brings down the cost and eases the adoption of technology. This will lead to radical new circumstances for offering eHealth services and constructing our new generation of healthcare information systems.

However, there are some limitations of this paper. Firstly, the respondents group of questionnaires was not so big due to our restrictive rules (over 55 and have at least one chronic disease), so the loss of care recipients' needs is possible. Secondly, as a patient-centered healthcare community, the requirements of care providers are gathered not so formal and detailed due to the time limitation, so there must be some uncover needs of the care providers.

\section{CONCLUSION}

This paper proposed an online virtual community for homebased chronic healthcare. The design idea is from online social networks. The requirements of the community were mainly gathered from the questionnaires with target group people. We use "user stories" of agile software development to describe the functional requirements and the non-functional requirements are briefly discussed. Finally a prototype is designed based on the requirements. In the future, we will show this prototype to the potential users for evaluation. And former interviews or surveys will be conducted through the healthcare providers to get more in-depth requirements in their perspectives. In the end, we will develop the online community based on cloud technology and put it into use as soon as possible.

\section{REFERENCES}

[1] H. Rheingold, The Virtual Community: Homesteading on the Electronic Frontier. MIT Press, 1993.

[2] "WHO | Chronic diseases and health promotion," WHO. [Online]. Available: http://www.who.int/chp/en/. [Accessed: 28-May-2014].

[3] "What is Chronic Disease? | Center for Managing Chronic Disease Putting People at the Center of Solutions." [Online]. Available: http://cmcd.sph.umich.edu/what-is-chronic-disease.html. [Accessed: 28May-2014].

[4] C.-C. Lin, R.-G. Lee, and C.-C. Hsiao, "A pervasive health monitoring service system based on ubiquitous network technology," Int. J. Med. Inf., vol. 77, no. 7, pp. 461-469, Jul. 2008

[5] C.-M. Chen, "Web-based remote human pulse monitoring system with intelligent data analysis for home health care," Expert Syst. Appl., vol. 38, no. 3, pp. 2011-2019, Mar. 2011.

[6] "HealthVault." [Online]. Available: https://www.healthvault.com/se/en. [Accessed: 02-Jul-2014].

[7] Y. Rogers, H. Sharp, and J. Preece, Interaction Design: Beyond Human - Computer Interaction. John Wiley \& Sons, 2011.

[8] "Guide to Agile Practices." [Online]. Available: http://guide.agilealliance.org/guide/user-stories.html. [Accessed: 08-Jun2014].

[9] M. Glinz, "On Non-Functional Requirements," in Requirements Engineering Conference, 2007. RE '07. 15th IEEE International, 2007, pp. 21-26.

[10] L. Chung and J. C. S. do P. Leite, "On Non-Functional Requirements in Software Engineering," in Conceptual Modeling: Foundations and Applications, A. T. Borgida, V. K. Chaudhri, P. Giorgini, and E. S. Yu, Eds. Springer Berlin Heidelberg, 2009, pp. 363-379.

[11] J. Nielsen, "Ten usability heuristics," 2005.

[12] M. L. Braunstein, Health informatics in the cloud. Springer, 2012.

[13] M. M. Goldstein, A. L. Rein, M. M. Heesters, P. P. Hughes, B. Williams, and S. A. Weinstein, "Data segmentation in electronic health information exchange: Policy considerations and analysis," 2010.

[14] J. Crinnion, Evolutionary Systems Development: A Practical Guide to the Use of Prototyping Within a Structured Systems Methodology. Perseus Publishing, 1992. 